\title{
Conjugate Heat Transfer Characteristics of Laminar Flows Through a Backward Facing Step Duct
}

\author{
Bayram CELIK ${ }^{* 1}$ \\ ${ }^{1}$ Istanbul Technical University, Faculty of Aeronautics and Astronautics, Astronautical Engineering Department, \\ 34469, Istanbul
}

(Alınış / Received: 12.01.2017, Kabul / Accepted: 09.09.2017, Online Yayınlanma / Published Online: 21.10.2017)

\section{Keywords}

Conjugate heat transfer, OpenFOAM,

Backward facing step duct, Finite volume method

\begin{abstract}
Present study investigates the effects of solid to fluid conductivity ratio, Prandtl and Reynolds numbers, and solid wall thickness on conjugate heat transfer for a backward facing step duct with a conductive solid bottom wall. Although Kanna and Das performed a case study in 2006 for the same problem, the benchmark studies conducted later including the present one revealed that their results are arguable. Ramsak states in a study "Professor Kanna has confirmed in personal communication that their results are probably wrong". The temperature and Nusselt number variations along the solid-fluid interface presented here are in excellent agreement with those obtained by Ramsak. The analyses presented here reveal that even though the decrease in Pr and the increase in solid to fluid conductivity ratio have similar global influence with the thinning wall on the interface temperature, the influence of the former parameters are limited in recirculation zone.
\end{abstract}

\section{Ters Basamak Şekilli Kanal İçerisindeki Laminer Akışın Eşlenik Isı Transferi Karakteristiği}

\author{
Anahtar Kelimeler \\ Eşlenik ısı transferi, \\ OpenFOAM, \\ Ters basamak şekilli kanal, \\ Sonlu hacimler yöntemi
}

\begin{abstract}
Özet: Bu çalışma iletken katı bir alt duvarı olan ters basamak şekilli bir kanal için, katının akışkana göre iletim oranı, katı duvarın kalınlı̆̆ı, Prandtl ve Reynolds sayılarının eşlenik ısı transferine etkilerini incelemektedir. 2006 yllında Kanna ve Das aynı problem için bir durum çalışması yapmış olmalarına rağmen, sunulan bu çalışmanın da dâhil olduğu sonraki yıllarda yapılan karşılaştırma çalışmaları Kanna ve Das'ın sonuçlarının tartışmalı olduğunu ortaya koymuştur. Ramsak çalışmasında "kişisel iletişim sırasında Profesör Kanna'nın elde ettikleri sonuçların muhtemelen yanlış olduğunu teyit ettiğini" belirtmektedir. Bu çalışmada sunulan ara yüzey boyunca sıcaklık ve Nusselt sayısı değișimleri Ramsak'ın elde ettikleri ile mükemmel bir uyum içerisindedir. Bu makalede sunulan analizler, her ne kadar Prandtl sayısındaki düşüşün ve katının akışkana iletim oranındaki artışın ara yüzey sıcaklığı üzerindeki genel etkisinin katı duvardaki incelmeyle benzer olduğunu ortaya koysa da, ilk iki parametrenin etkileri resirkülasyon bölgesinde sinırlıdır.
\end{abstract}

\section{Introduction}

In many cases, heat and mass transfers through or over a solid object requires consideration of conduction in solid region besides the convection in the fluid. Conjugate heat transfer (CHT) is an approach, where heat transfer in fluid flow is modeled without neglecting the conduction in the solid region or regions that are in contact with the fluid. CHT ensures that there is no jump in heat fluxes and temperatures at the solid fluid interface. With the advance in computational technology and parallel computing, the solvers with capability of conjugate heat transfer modelling are able to be applied to wide range of problems [1-3].

Although a backward facing step duct is a quite simple geometry, rich and complex flow physics that 
result from presence of separation, reattachment, multiple separation bubbles make it one of the most preferred benchmark problems in CFD literature. Flows with separation and reattachment encounter in diverse range of cooling applications, such as electronic devices, nuclear reactors, turbine blades, and combustion chambers. There are great numbers of studies focus on two-dimensional incompressible flow through a backward facing step duct up to $\mathrm{Re}=800$. [4-16]. Erturk conducted a comprehensive study to check whether $\mathrm{Re}=800$ was a limit for steady 2-D flow through a backward facing step duct [17]. Up to date there were only a few studies that were able to clearly show presence of steady numerical solution beyond $\operatorname{Re}=800[18,19]$. In one of those studies, Ramsak and Skerget used a subdomain boundary element method based on stream function vorticity formulation [18]. In another study, Cruchaga obtained solution using a finite element method that was based on generalized streamline operator technique [19]. Erturk obtained steady solutions up to $R e=3000$ using a finite difference Navier-Stokes solver with stream function and vorticity formulation.

Compared to the large number of two-dimensional studies aforementioned, there are limited number of three-dimensional computational studies in the literature. Li and Armaly [20], Saldana et al. [21], and Nie and Armaly [22] studied three-dimensional buoyant flows through a vertically aligned backward facing step duct.

Kanna and Das conducted a conjugate heat transfer study to determine the heat transfer characteristics of two dimensional backward facing step duct flow [23]. Their flow solver is based on stream-function vorticity formulation and uses alternating direction implicit (ADI) method to obtain velocity field in the fluid regime. Heat equation is solved in the solid and fluid region simultaneously. Kanna and Das investigated effects of thermal conductivity, step height ratio, Prandtl and Reynolds numbers on heat transfer characteristics by evaluating the interface temperatures and Nusselt numbers. In 2015, Ramsak [24] reconsidered a benchmark problem and noticed a mismatch between his and Kanna and Das' result. The fluid solver of Ramsak is also based on the stream function vorticity formulation. In order to be sure about mismatch they performed additional analysis using a commercial software and boundary element method, which also confirmed the inconsistency. This mismatch also reported in a conference proceeding by Teruel and Fagliato in 2013 [25].

The two studies aforementioned [24, 25] reveal that Kanna and Das' results are arguable. Moreover, Ramsak states in his study [24] that "Professor Kanna has confirmed in personal communication that their results published in [23] are probably wrong". On the other hand, there is no study available in the literature that provides analyses as Kanna \& Das intended. The studies in Reference [24, 25] are not able to go beyond a benchmark study. As a result, it is obvious that there is a need for a study that investigates the effects of $\mathrm{Pr}, \mathrm{Re}$, and conductivity ratio on heat transfer as Kanna \& Das tried. Present article responds to this need. In order to reach this goal a new solver is constructed by coupling two preexisting solvers of open source CFD code, OpenFOAM.

The objective of present study is to conduct a parametric study to investigate the effects of solid to fluid conductivity ratio, Prandtl and Reynolds numbers, and solid wall thickness on conjugate heat transfer for a backward facing step duct with a conductive solid bottom wall. To the best of our knowledge, the influence of the solid wall thickness on heat transfer has not been considered in any study and there is no reliable results on the influence of the other parameters in the literature.

\section{Material and Method}

\subsection{Governing equations}

Continuity, momentum and energy equations, Eq.'s 13 are solved for the fluid region.

$$
\begin{gathered}
\nabla \cdot \boldsymbol{u}=0 \\
\frac{\partial \boldsymbol{u}}{\partial t}+\boldsymbol{u} \cdot \nabla \boldsymbol{u}=\frac{1}{\rho} \nabla p+v \nabla^{2} \boldsymbol{u} \\
\frac{\partial T_{f}}{\partial t}+\boldsymbol{u} \cdot \nabla T_{f}=\alpha \nabla^{2} T_{f}
\end{gathered}
$$

In the equations above, $\boldsymbol{u}, p, \rho, T_{f}, t, v$, and $\alpha$ are velocity vector, pressure, density, fluid temperature, time, kinematic viscosity, and thermal diffusivity, respectively. On the other hand, in the solid domain that is in contact with the fluid region, the equation below needs to be solved.

$$
\frac{\partial T_{s}}{\partial t}=\alpha \nabla^{2} T_{s}
$$

where $T_{s}$ and $\alpha$ are the temperature and thermal diffusivity of the solid, respectively. At the interface of the solid and fluid domain, the conditions of no jump in the temperatures and heat fluxes are satisfied by using the following equations.

$$
\begin{gathered}
T_{f}=T_{s} \\
k_{f}\left(\frac{\partial T}{\partial n}\right)_{f}=k_{s}\left(\frac{\partial T}{\partial n}\right)_{s}
\end{gathered}
$$

In the equations above, $k_{f}$ and $k_{s}$ are the thermal conductivities of fluid and solid, respectively. 


\subsection{Numerical methods}

OpenFOAM is an open source CFD package that is able to solve partial differential equations and obtain solution for wide range of fluid flow problems. It is based on finite volume method. In this study, a new solver is constructed by using two preexisting solvers of the OpenFOAM [26-27]. The solvers consider dimensional form of the governing equations.

Energy balance at the solid fluid interface given in Eq. (6) can be written explicitly as follows:

$$
k_{f} \frac{T_{f}-T_{w}}{\Delta_{f}}=k_{s} \frac{T_{w}-T_{s}}{\Delta_{s}}
$$

, where $\Delta_{f}$ and $\Delta_{s}$ are the distance normal to the wall direction in fluid and solid regions, respectively. The interface temperature $T_{w}$ can be derived from the equation above as follows.

$$
T_{w}=\frac{k_{f} \Delta_{s} T_{f}+k_{s} \Delta_{f} T_{s}}{k_{f} \Delta_{s}+k_{s} \Delta_{f}}
$$

Substituting the derived interface temperature expression into the heat flux equations, separate Neumann boundary conditions are obtained on the wall for the fluid and solid regions. The Neumann boundary conditions that are applied on the solid fluid interface are written below explicitly.

$$
\begin{aligned}
& \left(\frac{\partial T}{\partial n}\right)_{f}=\frac{k_{s}\left(T_{f}-T_{s}\right)}{k_{f} \Delta_{s}+k_{s} \Delta_{f}} \\
& \left(\frac{\partial T}{\partial n}\right)_{s}=\frac{k_{f}\left(T_{s}-T_{f}\right)}{k_{f} \Delta_{s}+k_{s} \Delta_{f}}
\end{aligned}
$$

At each time step, Neumann type of boundary conditions are prescribed on the interface for the fluid and the solid regions separately according to the two equations written above. Then the energy equations of two regions, Eq. (3) and (4) are solved. After the solutions, the errors in the interface values of temperate and heat fluxes are calculated from the following two equations.

$$
\begin{array}{r}
T_{\text {err }}=\left|T_{s}-T_{f}\right| \\
\text { Flux }_{\text {err }}=\left|k_{f} \frac{\partial T_{f}}{\partial n}-k_{s} \frac{\partial T_{s}}{\partial n}\right| \quad \text { On the interface (10) }
\end{array}
$$

Conjugate heat transfer computations are conducted by performing inner iterations after updating the boundary conditions until the errors reach the desired accuracy. In this study, inner iterations are continued for $10^{-5}$ accuracy.

\subsection{The conjugate heat transfer solver}

The developed solver consists of two separate solvers, one for fluid and the other for solid regions.
For fluid region, energy equation is added to the preexisting transient incompressible solver, icoFoam. icoFoam uses Pressure-Implicit with Splitting of Operators, PISO algorithm in the solution of incompressible Navier-Stokes equation. It reads solution parameters, such as maximum iteration number and error tolerances from an input file, fvSchemes. The solver used in solid region is adapted from another preexisting solver of laplacianFoam.

In order to obtain two separate solutions on two separate regions of fluid and solid, the solid and fluid meshes need to be introduced to the solver. There are several examples of multi region solvers in OpenFOAM for steady and unsteady compressible conjugate heat transfer problems. Modular structure of openFOAM allows users to introduce two separate meshes by adding new entry for solid mesh and renaming the original mesh as fluid mesh in createMesh.H file. Then the energy equations for fluid and solid regions are introduced to the solver by adding them to the end of the PISO loop with include command. A flow chart for the developed solver is shown in Figure 1.

\subsection{Discretization of the PDE in OpenFOAM}

OpenFOAM solvers can use predefined classes of two static functions, finiteVolumeMethod and finiteVolumeCalculus [27]. One wishing to solve a partial differential equation, can call those predefined functions and discretize each term in the PDE in explicit or implicit manners. For example, the syntax given below corresponds to implicit solution of transient diffusion equation given in Eq. (4).

$$
\text { fvm::ddt(Ts) == alfa*fvm :: laplacian (Ts) }
$$

The term fvm that appear in the expression above stands for the predefined function finiteVolumeMethod. The left and right hand side of the expression represent the temporal and spatial discretization of the terms in the PDE. A list of predefined discretization schemes are available in Reference [27]. ddt term corresponds to Euler implicit scheme and it is first order accurate. Another fvSchemes class object available in OpenFOAM is laplacian. Discretization of each term via finite volume method is formulated by integrating the term over a cell volume, V. Integration of the term over a control volume with Gauss's theorem is as follows.

$$
\int_{V} \nabla \cdot\left(\alpha \nabla T_{s}\right) d V=\int_{S} d \boldsymbol{S} \cdot\left(\alpha \nabla T_{S}\right)=\sum_{f} \alpha S_{f}\left(\nabla T_{s}\right)_{f}
$$

where $\boldsymbol{S}$ is the surface area vector. The solver reads type of the temporal and spatial discretizations from fvSchemes. In this study, the schemes are Euler backward and Gauss linear corrected, respectively. 


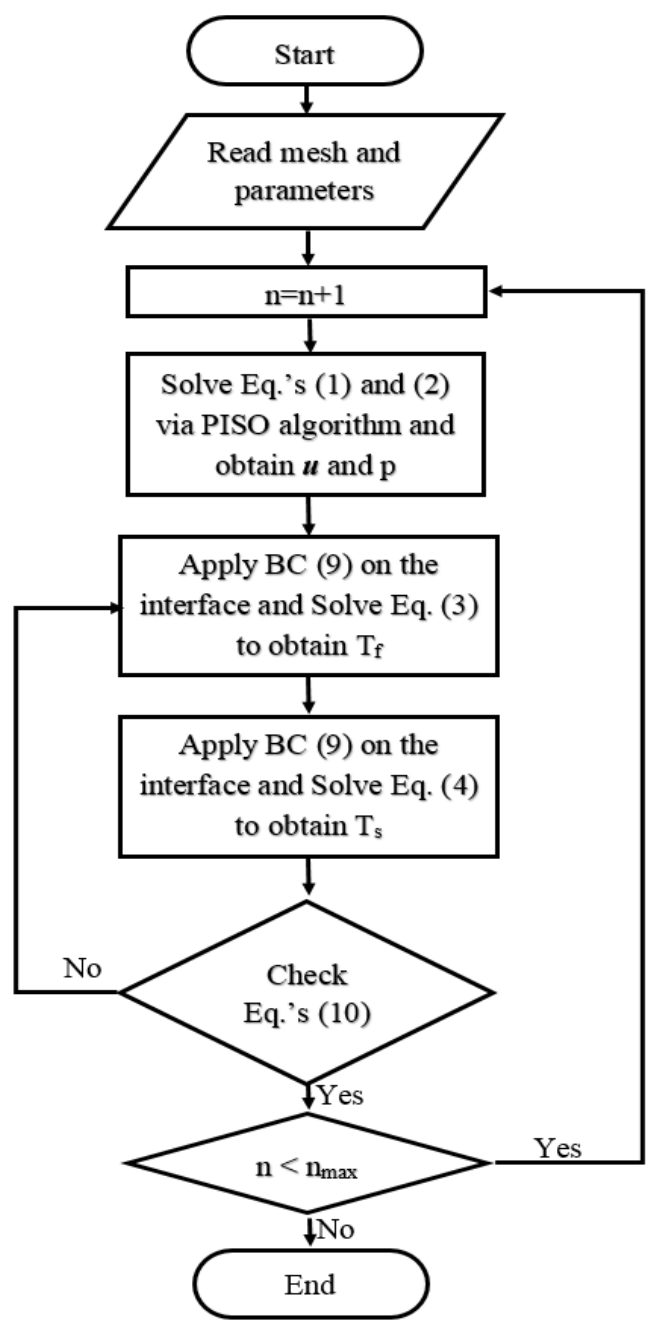

Figure 1. Flow chart of the developed solver.

\section{Results}

The developed solver has been tested and validated before for several benchmark problems, conjugate heat transfers for Couette and backward facing step duct flows [28]. The benchmark problem of conjugate heat transfer is reconsidered here and the obtained results are evaluated in terms of mesh independency and accuracy. Effects of flow parameters are investigated by varying the fluid to solid thermal conductivity ratio, channel height to wall thickness ratio, Prandtl and Reynolds numbers.

\subsection{Computational details and validation}

Geometrical details, boundary and initial conditions of the problem are depicted in Figure 2. The fluid at 0 temperature enters the channel from the top left. At the inlet, fully developed flow, a parabolic profile with an average value of 1 is set as velocity boundary condition on the upper section of the channel as in the reference studies [23-25, 28]. The upper wall of the channel is adiabatic. No slip and zero pressure gradient boundary conditions are applied on the channel walls. At the outlet, zero gradient boundary condition is set for temperature and velocity. The left and right boundaries of the solid region are adiabatic. On the interface of solid and fluid regions, no boundary condition is prescribed. Instead, the interface temperature is determined iteratively as described in the previous section. Reynolds and Prandtl numbers are equal to 800 and 0.71, respectively. Solid to fluid conductivity and step height to wall thickness ratios are set to be equal to 10 and 4 , respectively.

Velocity magnitude contours for fluid and temperature contours for both fluid and solid regions are shown in Figures 3 and 4. As can be seen from the figures the cold fluid entering from the left reattaches on the solid wall at approximately $x / b=6$, where the temperature is the minimum at the solid fluid interface. A sharp decrease in the interface temperature turns into a steep rise after the reattachment point because of thickening boundary layer. After the reattachment point, the cold fluid in contact with the relatively hot solid wall is heated. A hot spot that appears in the fluid region extending from $x / b=0$ to the reattachment point results from the fluid trapped between the entering fluid stream and the channel. The correlation between the temperature contours of the flow field and solid regime are obvious from Fig. 4. The black line represents the solid fluid interface.

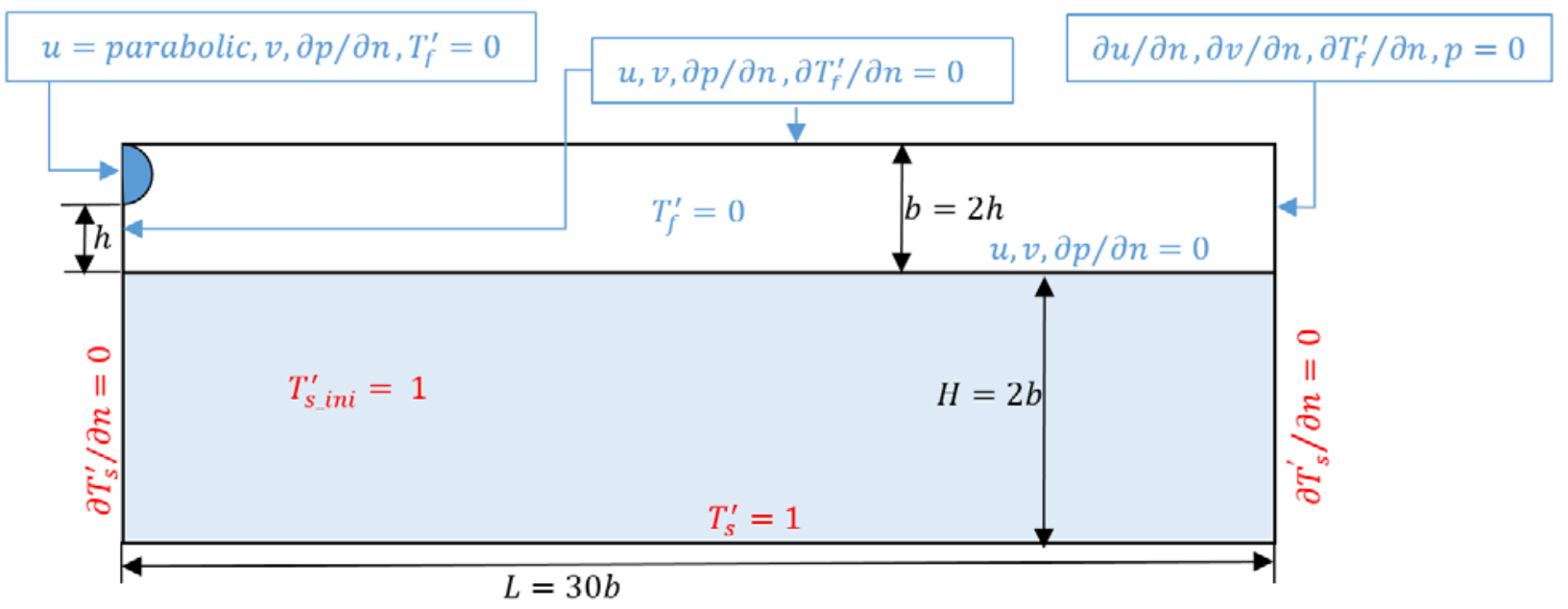

Figure 2. Geometric details, initial and boundary conditions. 
$|\mathrm{U}|$

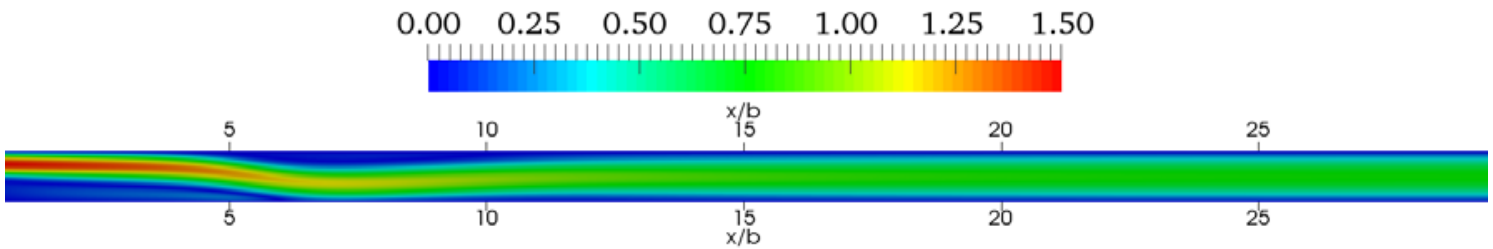

Figure 3. Velocity magnitude contours, $(\operatorname{Re}=800, \operatorname{Pr}=0.71$, and $h r=4)$

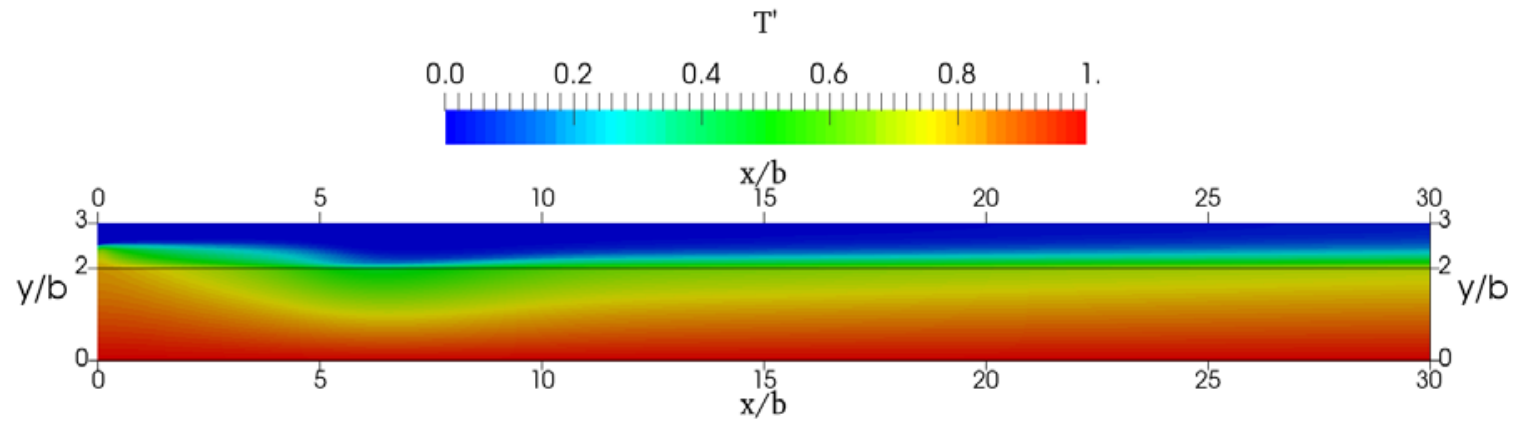

Figure 4. Temperature contours, $(\operatorname{Re}=800, \operatorname{Pr}=0.71$, and $\mathrm{hr}=4)$

Nondimensional temperature distributions along the fluid solid interface and variation of the normalized velocity magnitude along the channel centerline are shown in Figures 5.a and b, respectively. The results are obtained using three different meshes; the course, the fine, and the finest. The total cell number of the meshes for fluid region are $770 \times 24,900 \times 30$, and 1200x40 and the cells are identical. The total cell number for solid region in vertical direction is equal to the half of the cell number in fluid region. As can be seen from the figure of both velocity and temperature distributions, the discrepancy between the results are barely visible. The maximum differences in temperature and velocity magnitude is less than $0.09 \%$ and $0.04 \%$ for the results with the fine and the finest meshes. This comparison proves that the obtained results are mesh independent. All the analysis presented in the following sections are obtained using the finest mesh.

In order to show the quality of the mesh used in the study, $1 / 10^{\text {th }}$ of the finest mesh resolution is plotted in Figure 6, where gray and blue portions represent the fluid and solid regions, respectively.

Variations of obtained interface temperature and Nusselt number for $\mathrm{Re}=800, \mathrm{Pr}=0.71$, and $\mathrm{H} / \mathrm{h}=4$ are plotted in Figure 7 and compared with the References available in literature $[23,24]$. As stated before, there is a significant mismatch between the results in literature. The results presented here are in good agreement with Ramsak's result. The maximum deviation between the results is less $0.6 \%$.

\subsection{Effect of reynolds number}

Erturk has studied the effects of Reynolds number on physics of the flow through a backward facing step duct for Reynolds number up to 3000 [17]. His detailed study focuses on flow physics.
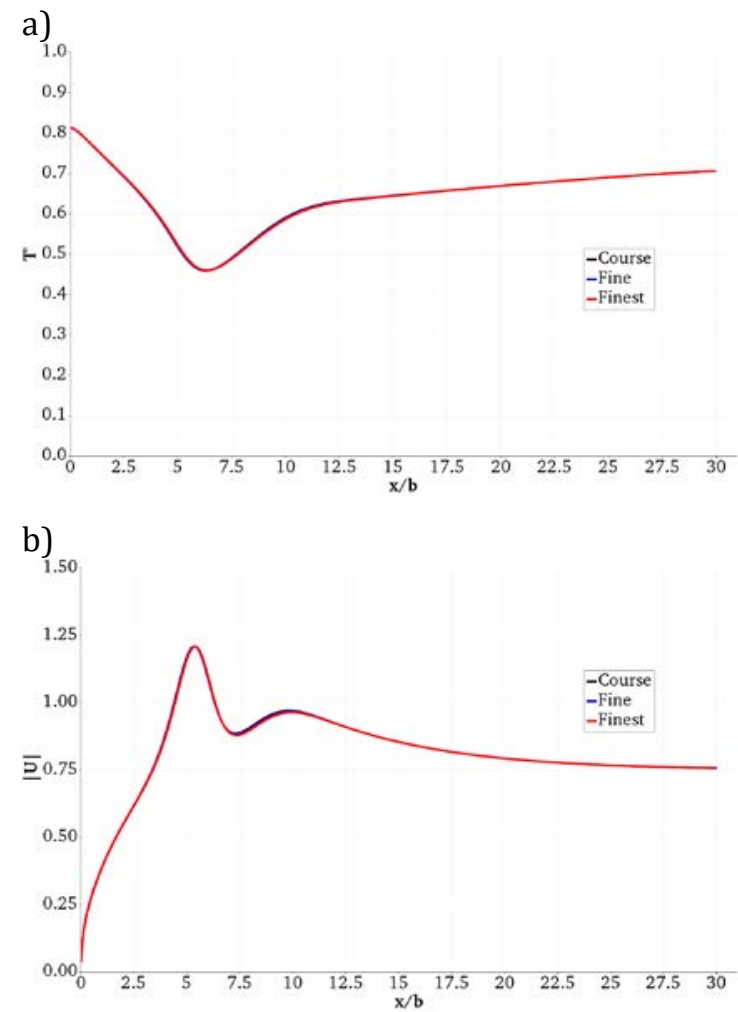

Figure 5. Nondimensional temperature a) and velocity magnitude distributions b) along the solid fluid interface and channel centerline

In this section, effects of flow physics on conjugate heat transfer are investigated by varying $\mathrm{Re}$ but keeping the channel geometry the same. In Figure 8, temperature contours on both regions as well as the streamlines that identify the location and sizes of the separation bubbles formed on the top and bottom walls of the channel are shown for $\mathrm{Re}=200,400,600$, and 800. Pr and $\mathrm{kr}$ are equal to 0.71 and 10 . The influence of the cold fluid that impinges on the solid surface are visible at all Re. Development of the thermal boundary layer downstream of the 
impingement point can be also seen from the figure. Thermal boundary layer gets thinner as Re increases. The separation bubble forming on the top wall of the channel is not visible for $\mathrm{Re}<400$, and both bubbles enlarge as Reynolds number increases. This observation confirms the results by Erturk [17].

Variations of interface temperatures at $\mathrm{Re}=200,400$, 600, and 800 are shown in Figures 9.a and b for two different values of fluid to solid conductivity ratio, $\mathrm{kr}=1$ and 10 . The solid wall thickness to entrance height ratio, hr and Pr are equal to 4 and 0.71 . As can be seen from the figures, an increase in Re extends the temperate drop zone along the channel direction because of enlarging recirculation zone. The interface reaches the lowest temperature value at a point, where the cold fluid meets the solid surface. The interface temperatures rise sharply after the reattachment point. The sharp rises turn into linear increases because of thickening thermal boundary layers. The sharp rise in temperature distribution becomes more apparent as Re is increased. Although the local values of interface temperatures rise significantly with increased $\mathrm{kr}$, general trends of them are dictated by the flow physics, and thereby they are conserved for all the Re considered here

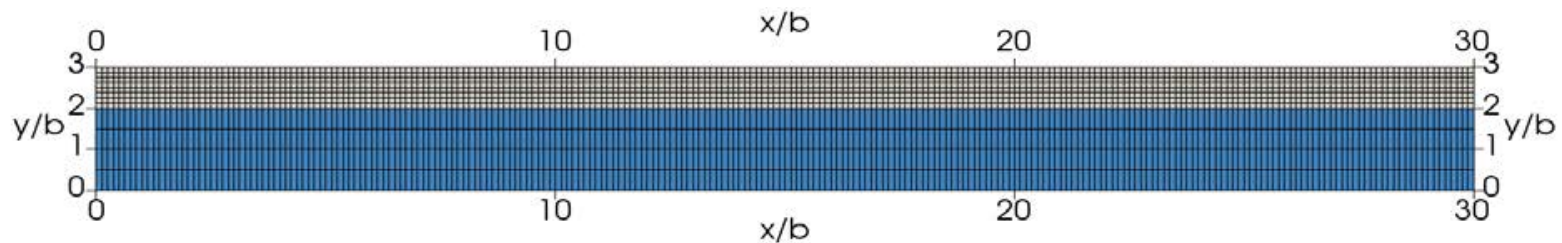

Figure 6. Computational mesh

a)

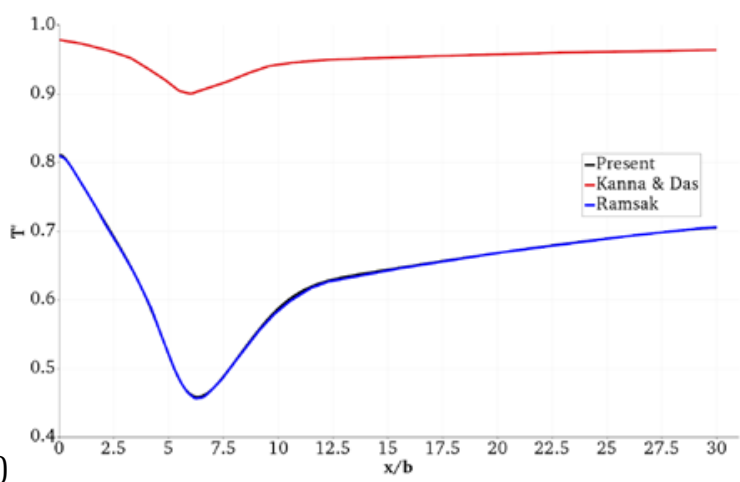

b)

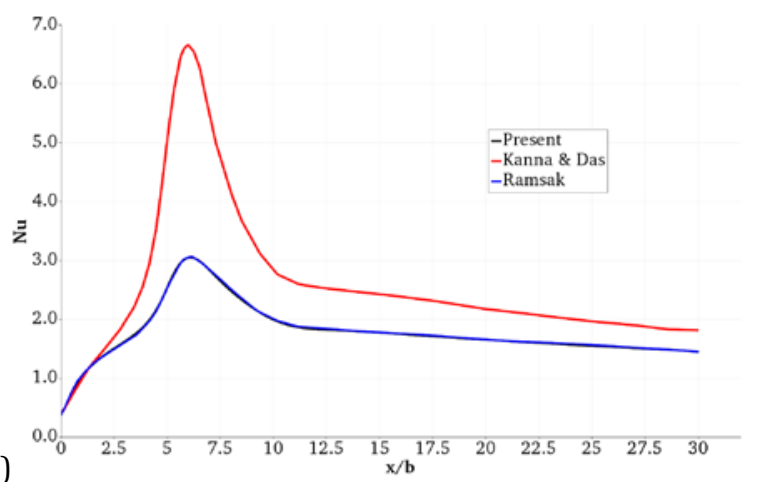

Figure 7. Comparison of obtained interface temperature a) and Nusselt number distributions b) with the Reference studies [Ramsak, Kanna \& Das]. $(\operatorname{Re}=800, \operatorname{Pr}=0.71$, and $h / b=4)$

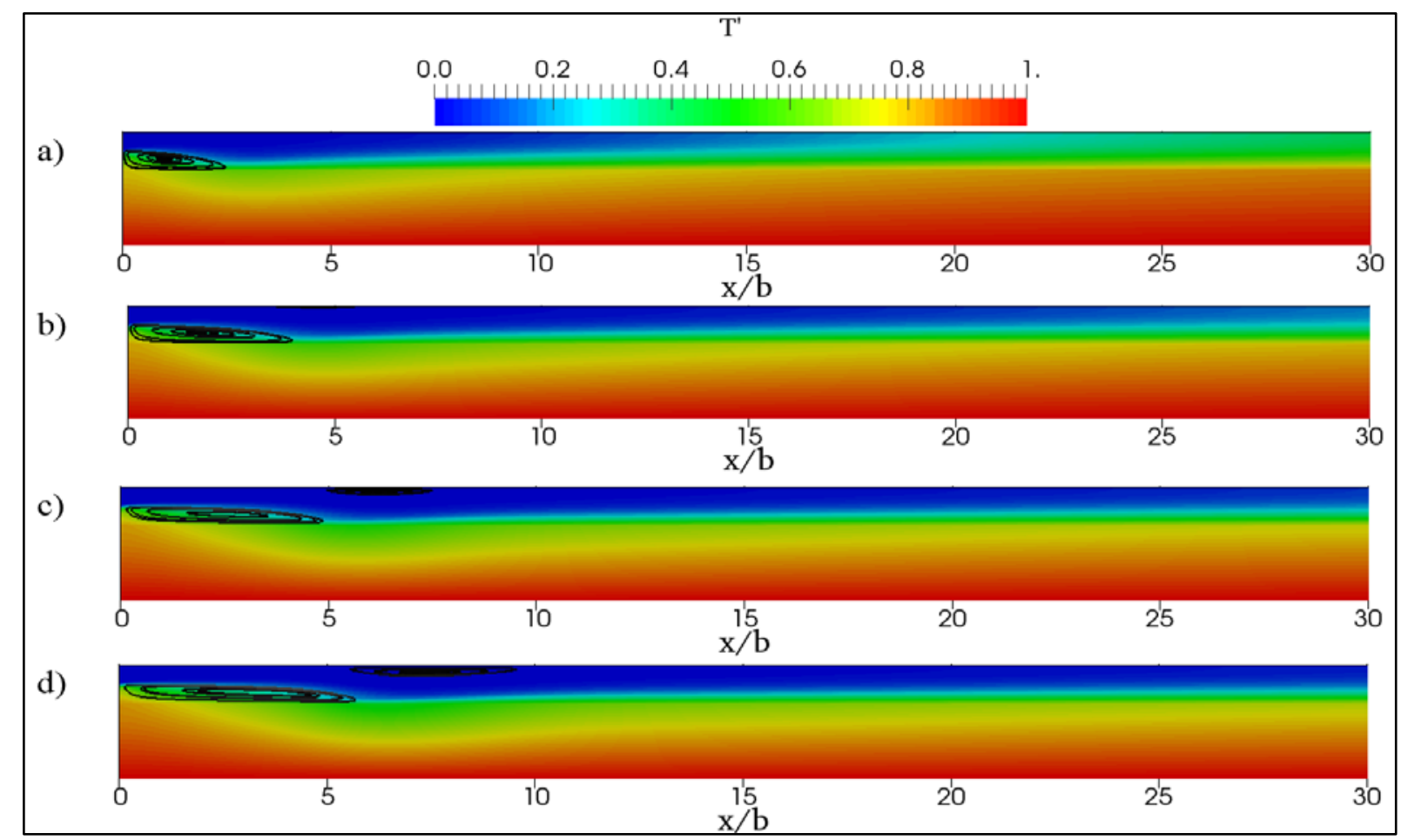

Figure 8. Temperature contours and separation bubbles streamlines representing streamlines at $\operatorname{Re}=200 \mathrm{a}$ ), $\operatorname{Re}=400 \mathrm{~b}$ ), $\mathrm{Re}=600 \mathrm{c}$ ), and $\mathrm{Re}=800 \mathrm{~d}$ ). 
Variation of local $\mathrm{Nu}$ along the interface are plotted in Figure $10 \mathrm{a}$ ) and b) for $\mathrm{kr}$ values of 1 and 10, respectively. As can be seen from the figures, average $\mathrm{Nu}$ values drop significantly as $\mathrm{kr}$ is increased. Increased $\mathrm{kr}$ amplifies the peak in $\mathrm{Nu}$ distributions at the reattachment point.

In Figure's. 11.a and b, effects of Re on the interface temperature are shown for $\operatorname{Pr}=1$ and 10 , where $\mathrm{H} / \mathrm{h}$

a)
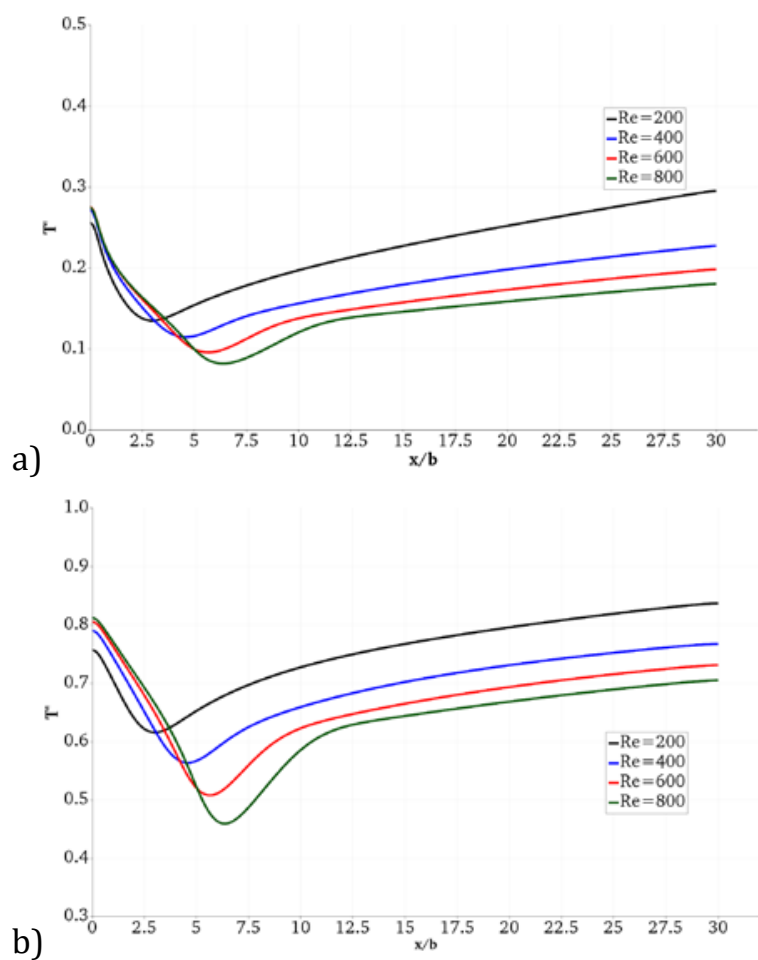

Figure 9. Interface temperature distributions for $\mathrm{kr}=1$ a) and $\mathrm{kr}=10 \mathrm{~b})(\mathrm{h} / \mathrm{b}=4$ and $\operatorname{Pr}=0.71)$

a)
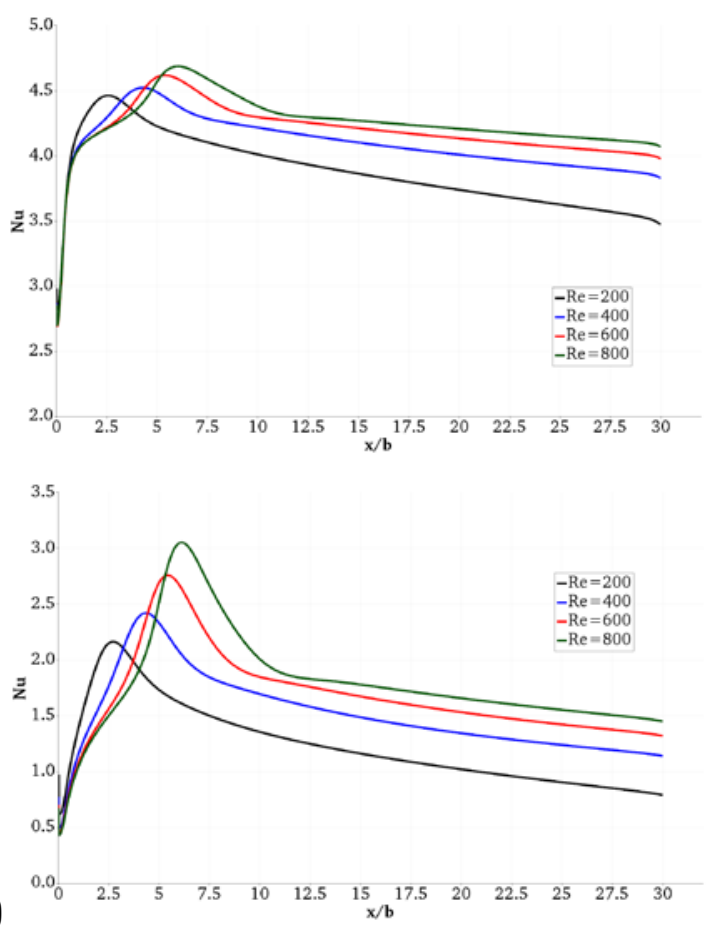

Figure 10. Interface Nusselt Number distributions for $k r=1 \mathrm{a})$ and $\mathrm{kr}=10 \mathrm{~b}$ ) (h/b=4 and $\operatorname{Pr}=0.71)$ and $\mathrm{kr}$ are equal to 4 and 10, respectively. Comparison of the distributions for the cases with $\operatorname{Pr}=1$ and 10 shows that Re effect is more apparent in both upstream and downstream of the separation point for low Pr.

The local Nu variations along the interface are plotted in Figures 12.a and $b$ for $\operatorname{Pr}=1$ and 10. It is obvious

a)
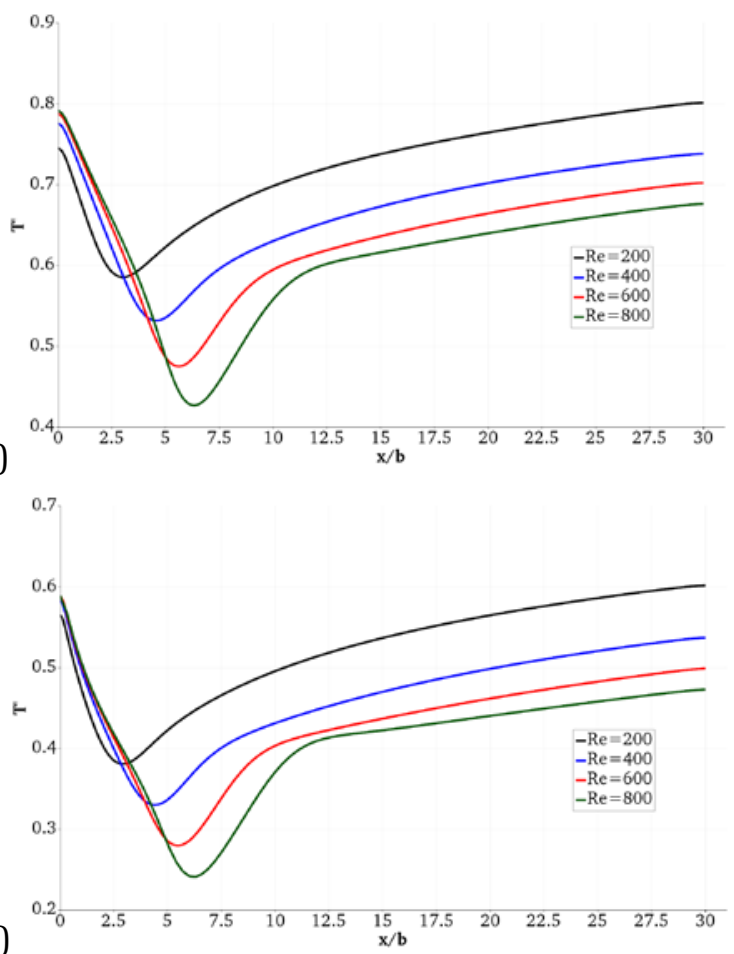

Figure 11. Interface temperature distributions for $\operatorname{Pr}=1$ a) and $\operatorname{Pr}=10 \mathrm{~b}$ ) ( $\mathrm{hr}=4$ and $\mathrm{kr}=10)$.

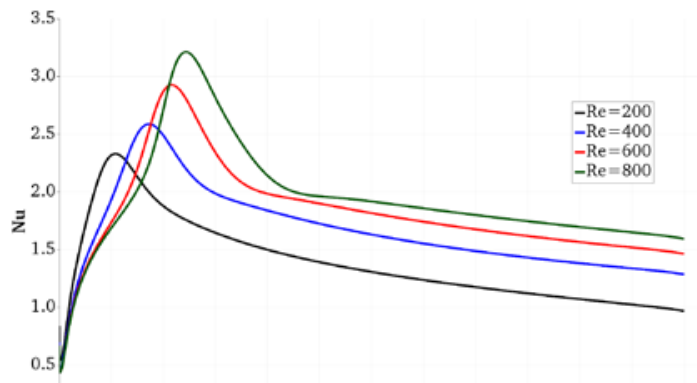

a)
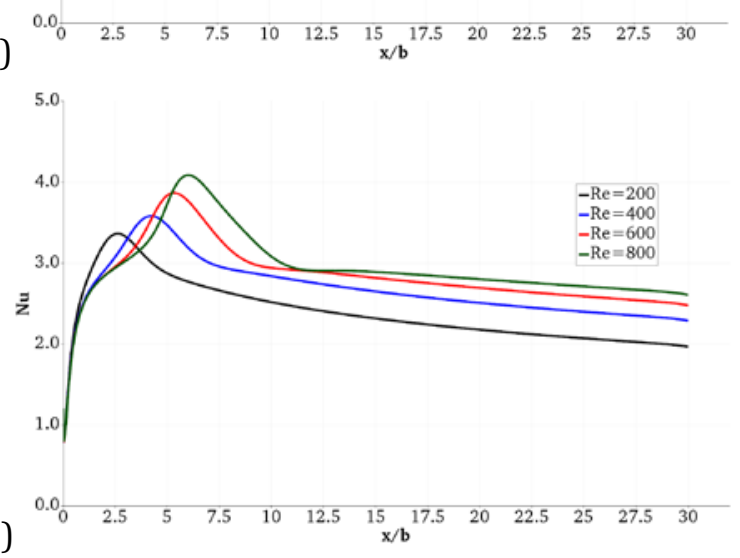

Figure 12. Interface Nusselt number distributions for $\operatorname{Pr}=1 \mathrm{a})$ and $\operatorname{Pr}=10 \mathrm{~b})(\mathrm{h} / \mathrm{b}=4$ and $\mathrm{kr}=10)$ 
from the figure that increased Pr enhances the overall heat transfer. The heat transfer efficiency decreases linearly after $\mathrm{x} / \mathrm{b}=11$ approximately.

\subsection{Effect of thermal conductivity}

Effects of thermal conductivity on interface temperature distributions are shown in Figures. 13.a through $\mathrm{d}$ for four different Re values. As can be seen from the figure, increased thermal conductivity causes global rise in the interface temperature distributions

Increased thermal conductivity ratio smooths out the temperature peak appearing near the reattachment point. The effect of conductivity ratio is apparent at all the Re studied here. The case, where the solid to fluid conductivity ratio goes to infinity corresponds to a state, where the solid fluid interface at constant temperature of 1 .

\subsection{Effect of solid wall thickness}

Effect of solid wall thickness on the interface temperature and $\mathrm{Nu}$ distributions are depicted in Figures 14. $a$ and $b$ for $\operatorname{Re}=200, \operatorname{Pr}=0.71$, and $k r=10$. As can be seen from the figure, decreased solid wall thickness causes overall rise in the interface temperature distribution. The case with zero solid wall thickness corresponds to the backward facing step duct, lower side of which is at constant temperature of 1. It is apparent from Fig. 14.b. that increased solid wall thickness causes maximum

decrease in heat transfer near the reattachment point.

a)

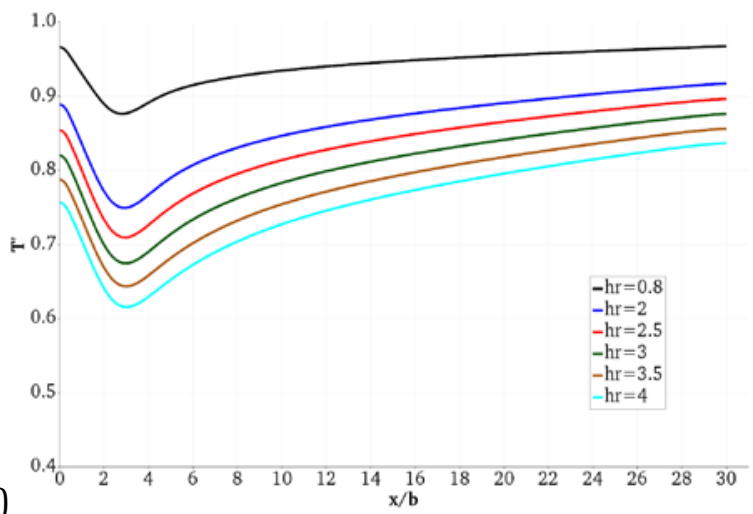

b)

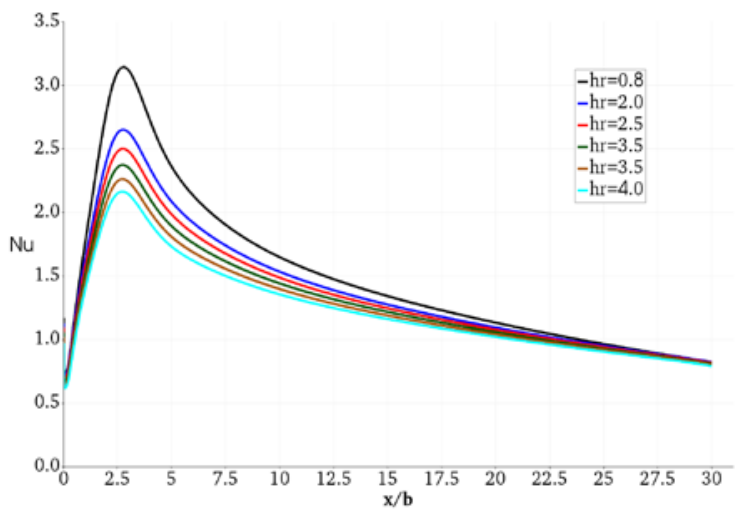

Figure 14. Effect of solid wall thickness on interface temperature a) and $\mathrm{Nu}$ b) distributions, $(\mathrm{Re}=200, \operatorname{Pr}=0.71$, $\mathrm{kr}=10$ ).

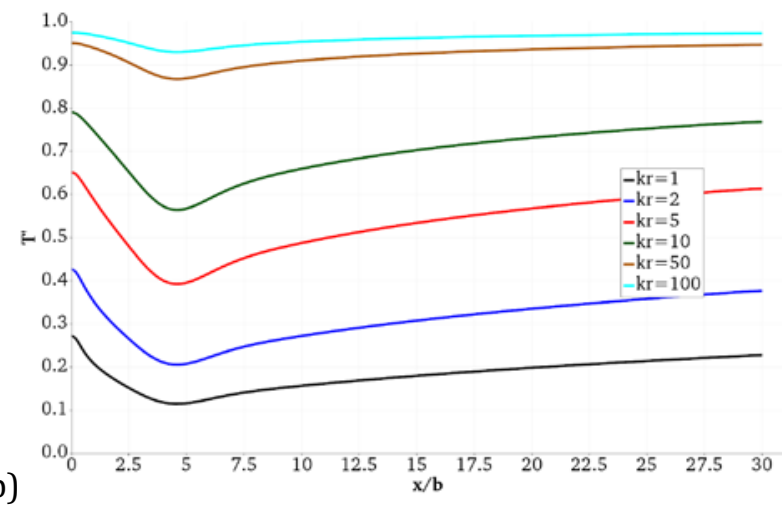

a)
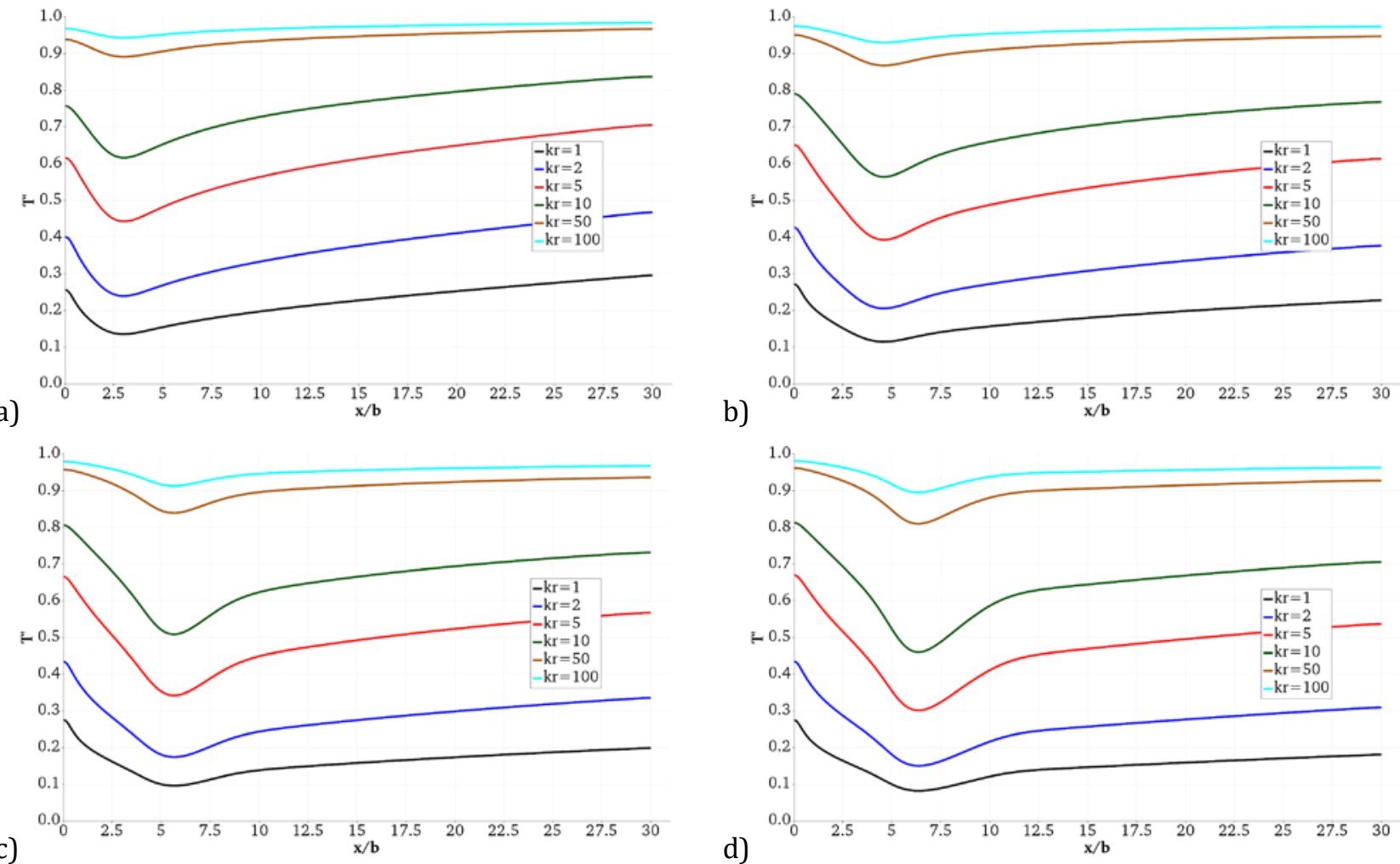

Figure 13. Effect of conductivity ratio on interface temperature distributions for $\operatorname{Pr}=0.71$, and $H / b=4$, at $\operatorname{Re}=200 \mathrm{a}$ ), $400 \mathrm{~b}$ ), $600 \mathrm{c}$ ), and $800 \mathrm{~d}$ ). 
a)

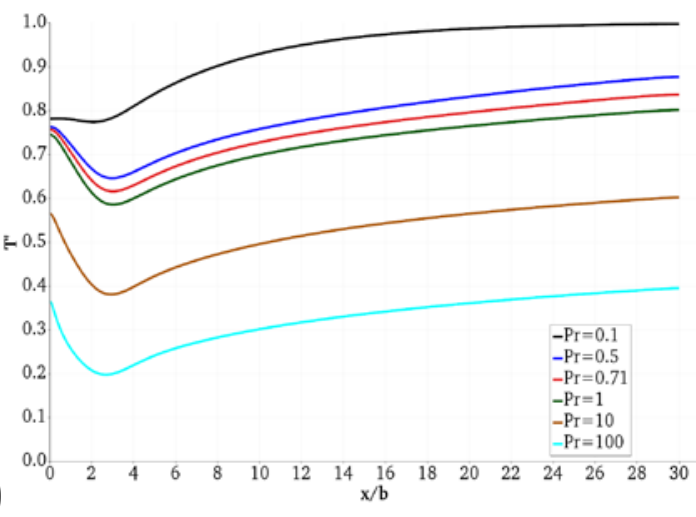

c)

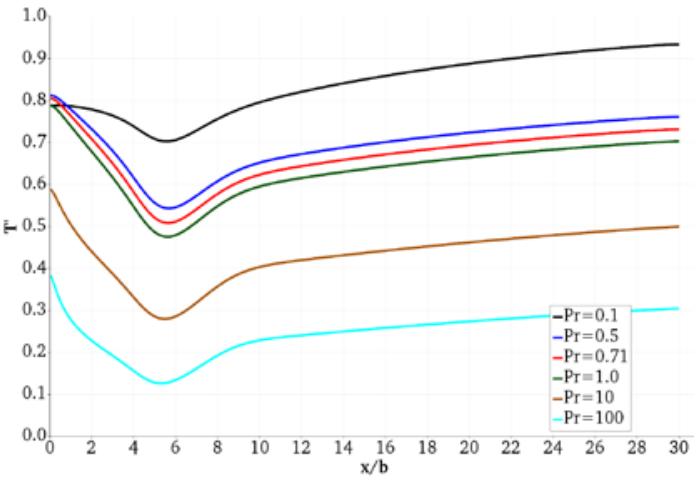

b)

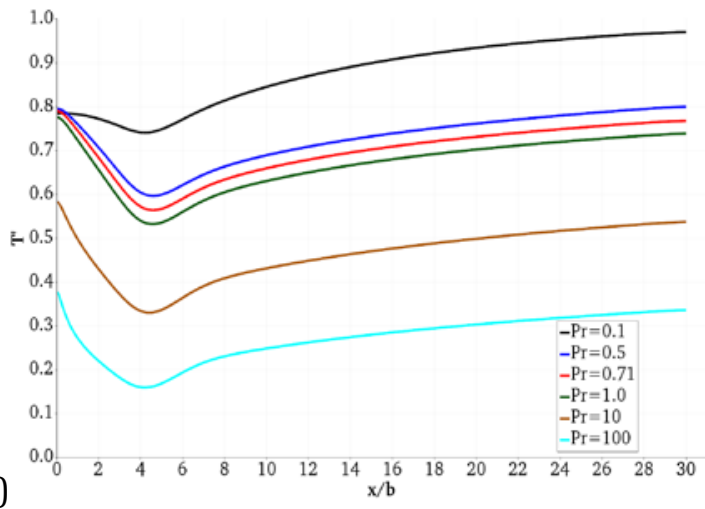

d)

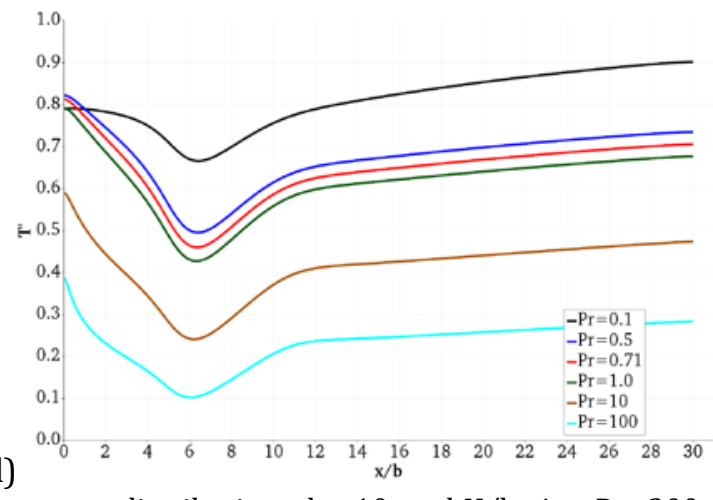

Figure 15. Effect of thermophysical properties on interface temperature distributions, $\mathrm{kr}=10$, and $\mathrm{H} / \mathrm{b}=4 \mathrm{at} \mathrm{Re}=200 \mathrm{a}$ ), 400 b), $600 \mathrm{c}$ ), and $800 \mathrm{~d}$ )

\subsection{Effect of prandtl number}

Interface temperature distributions at $\mathrm{Re}=200,400$, 600 , and 800 are obtained for the cases with $\operatorname{Pr}=0.1$, $0.5,0.71,1.0,10$, and 100. The distributions for $\mathrm{Re}=200,400,600$, and 800 are depicted in Figures 15.a, b, c, and d, respectively. The conductivity ratio, $\mathrm{kr}$ is set to be equal to 10 for the considered cases. As can be seen from the four different Re plots given in the figure, increased Pr causes overall drop in surface temperature distribution with exception of $\operatorname{Pr}=0.1$. Interface temperature distribution of the case with $\operatorname{Pr}=0.1$ differs from the others in the vicinity of $x / b=0$ (see Figure 3). This behavior results from presence of a flow region at $\mathrm{x} / \mathrm{h}=0$ that is not effected by the entering fluid stream. The effect of $\mathrm{Pr}$ is apparent at all the Reynolds numbers considered here.

\section{Discussion and Conclusion}

Present study introduces a conjugate heat transfer solver that is constructed by combining two preexisting solvers of an open source CFD solver, OpenFOAM. The solver is able to model laminar flows of Newtonian fluid and obtain temperature distribution on the fluid domain. Temperature field on the solid domain is obtained separately by solving the heat conduction equation. Then, the developed solver performs inner iteration to ensure whether the energy fluxes from one region to the other are in balance and there is no jump in the temperature. The solver is validated by solving the conjugate heat transfer problem proposed by Kanna Das, and later studied by Ramsak. Although Kanna \& Das has performed a comprehensive analysis for the geometry studied here, the two studies published later on were not able to confirm their results. Our results confirm the mismatch between the studies of Kanna \& Das and the others. Therefore, a conjugate heat transfer studies of Kanna \& Das are reconsidered here by designing and conducting a parametric study. The important findings of present study are summarized below:

Increased Re enhances heat transfer downstream of the reattachment point considerably, and the temperature drop that is taking place upstream of the impingement point becomes more dramatic. Decreased solid wall thickness causes overall rise in the interface temperature. Although the decreases in Pr and the increases in solid to fluid conductivity ratio have similar influence on the interface temperature distribution, their behaviour differs in the recirculation zone. Thinning out the solid wall rises temperature throughout the solid fluid interface. Depending on the desired outcome, a combination of the parameters studied here can be taken into account at the same time. Extension of the present study to 3-D and consideration of turbulent flow at higher Re will allow one to characterize CHT behaviour of a practical engineering design.

\section{Acknowledgment}

This study is supported by Istanbul Technical University (BAP project No: 36592). 


\section{References}

[1] Mensch, A. and Thole, K., 2015, Conjugate heat transfer analysis of the effects of impingement channel height for a turbine blade end wall, Heat and Mass Transfer, 82, 66-77.

[2] Sosnowski, P., Petronio A., Armenio, V., 2013, Numerical model for thin liquid film with evaporation and condensation on solid surfaces in systems with conjugated heat transfer, International Journal of Heat and Mass Transfer, 66, 382-395.

[3] Cintolesi, C., Nilsson, H., Petronio, A., Armenio V., 2017, Numerical simulation of conjugate heat transfer and surface radiative heat transfer using theP1 thermal radiation model: Parametric study in benchmark cases, International Journal of Heat and Mass Transfer, 107, 959-971.

[4] Gresho, P.M., Gartling, D.K., Torczynski, J.R., Cliffe, K.A., Winters, K.H., Garratt, T.J., 1993, Is the steady viscous incompressible twodimensional flow over a backward-facing step at Re $=800$ stable? , Int. J. Numerical Methods Fluids 17, 501-541.

[5] Keskar, J., Lyn, D.A., 1999, Computations of a laminar backward-facing step flow at $\mathrm{Re}=800$ with a spectral domain decomposition method, Int. J. Numerical Methods Fluids, 29, 411-427.

[6] Gartling, D.K., 1990, A test problem for outflow boundary conditions - flow over a backwardfacing step. Int. J. Numerical Methods Fluids, 11, 953-967.

[7] Papanastasiou, T.C., Malamataris, N., Ellwood, K., 1992, A new outflow boundary condition, Int. J. Numerical Methods Fluids, 14, 587-608.

[8] Rogers, S.E., Kwak, D., 1991, An upwind differencing scheme for the incompressible Navier-Stokes equations. Appl. Numer. Math., 8, 43-64.

[9] Kim, J., Moin, P., 1985, Application of a fractional-step method to incompressible Navier-Stokes equations. J Comp Phys., 59, 30823.

[10] Barton, I.E., 1997, The entrance effect of laminar flow over a backward facing step geometry, Int. J. Numerical Methods Fluids, 25, 633-44.

[11] Barton IE., 1998, Improved laminar predictions using a stabilized time dependent simple scheme, Int. J. Numer. Methods Fluids, 28, 84157.

[12] Sani, R.L, Gresho, P.M., 1994, Resume and remarks on the open boundary condition mini symposium, Int J Numer Methods Fluids, 18, 983-1008.
[13] Sheu, T.W.H., Tsai, S.F., 1999, Consistent Petrov Galerkin finite element simulation of channel flows, Int. J. Numer. Methods Fluids, 31, 1297310.

[14] Biagioli, F., 1998, Calculation of laminar flows with second-order schemes and collocated variable arrangement, Int J Numer Methods Fluids, 26, 887-905.

[15] Grigoriev, M.M., Dargush, G.F., 1999, A polyregion boundary element method for incompressible viscous fluid flows, Int J Numer Methods Eng. 1999, 46, 1127-58.

[16] Zang, Y., Street, R.L., Koseff, J.R., 1994, Grid A Non-staggered. Fractional step method for timedependent incompressible Navier-Stokes equations in curvilinear coordinates, J Comp Phys, 114, 18-33.

[17] Erturk, E., 2008, Numerical solutions of 2-D steady incompressible flow over a backwardfacing step, Part I: High Reynolds number solutions, Computers and Fluids, 37(6), 633655.

[18] Ramsak, M., and Skerget, L., 2004, A highly efficient multidomain BEM for multimillion subdomains, Eng. Anal. Bound. Elem. 43, 76-85.

[19] Cruchaga, M.A., 1998, A study of the backwardfacing step problem using a generalized streamline formulation, Commun Numer Methods Eng., 14, 697-708.

[20] Li, A. and Armaly, B.F., 2000, Convection Adjacent to a 3-D Backward-Facing Step," Proceedings of the 2000 (34th) National Heat Transfer Conference, Pittsburgh, PA, August 20 22, ASME Paper No. NHTC2000-12301.

[21] Barbosa Saldana J., and, N.K., Sarin V., 2005, Numerical Simulation of Mixed Convective Flow Over a Three-Dimensional Horizontal Backward Facing Step, Journal of Heat Transfer, 127, 10271036.

[22] Nie, J., and Armaly, B, 2003, Reattachment of Three-Dimensional Flow Adjacent to BackwardFacing Step, Journal of Heat Transfer, 125 (3), 422.

[23] Kanna, R.P., Das K.M., 2006, Conjugate heat transfer study of backward-facing step flow - A benchmark problem, International Journal of Heat and Mass Transfer, 49, 3929-3941.

[24] Ramsak, M. 2015, Conjugate heat transfer of backward-facing step flow: A benchmark problem revisited, International Journal of Heat and Mass Transfer, 84, 791-799.

[25] Teruel, F.E., Fogliatto, E., 2013, Numerical simulations of flow, heat transfer and conjugate heat transfer in the backward-facing step geometry, Mecanica, Computacional, vol. 32, Asociation Argentina de Mecanica Computacional 3265-3278 
[26] Craven, B.A., Campbell, R.A, Multi-Region Conjugate Heat/Mass Tansfers, http://www.personal.psu.edu/dab143/0FW6/T raining/craven slides.pdf (Last reached on 01.10.2017).

[27] OpenFOAM UserGuide, http://foam.sourceforge.net/docs/Guidesa4/ProgrammersGuide.pdf (Last reached on 01.10.2017).

[28] Topbas, B.S. Celik, B., 2015, Conjugate heat transfer analysis for internally cooled solid structure, 20. Ulusal Isı Bilimi ve Tekniği Kongresi, 2-5 September, Balıkesir, Turkey, 2015. 